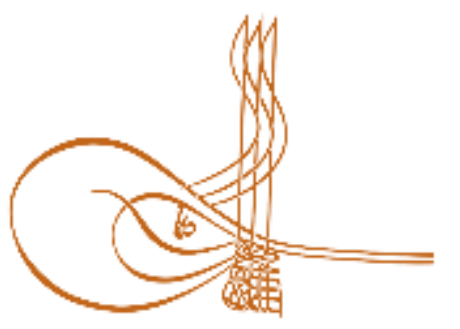

www.turkishstudies.net/turkishstudies
Turkish Studies

eISSN: $1308-2140$

Research Article / Araştırma Makalesi

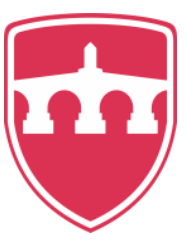

INTERNATIONAL

BALKAN

UNIVERSITY

Sponsored by IBU

\title{
Kutadgu Bilig'de Bir Üslup Özelliği Olarak -sA bolmaz Yapısı
}

\author{
As A Stylistic Feature The Structure -sA bolmaz In Kutadgu Bilig
}

\author{
Yaşar Tokay*
}

\begin{abstract}
Stylistics, which has a common place in linguistics and literature studies; developed as a branch of science used to reveal the language usage of the literary texts and the mental structure that constitutes the text. Kutadgu Bilig, as the name suggests, is a work written in Karahanid Turkish which is the standard language of the period in order to show the ways of being happy in every field and branch of both worlds. The work, written as a mesnevi, is not only a politician, it is a guide that gives important information about all points in the life of the society and the individual, sheds light on every stage of the social life and gives advice on various subjects. Grammar and morphology on the basis of the work on the stage of recording a certain point has been reached, while the work was written in the period of Karahanid Turkish and artists are seen to be very little on the stylistic studies. Considering the content characteristics of Kutadgu Bilig, it is seen that it was written as an advice book. Many different topics such as social values, family life (relationships with spouses and children), eating and drinking manners, speaking styles, the application of rules in various places and health constitute the subject of Kutadgu Bilig. It would not be wrong to say that a unique style and style is reflected on every page of the work in the sections where these subjects are explained. The formal and semantic dimensions that make up the style outlined indicate that the work should be evaluated as a whole. In this article, the phrase -sA bolmaz is discussed and its place in semantic structure, semantic indicators, usage areas and contribution to the formation of style are emphasized. In the seventeen samples discussed, it was found that sA bolmaz group affects the meaning at three points. It was seen that the meaning frame was shaped around certainty, general validity and subjective thoughts.
\end{abstract}

Structured Abstract: Style is at the crossroads of language and literature studies as a branch of science. These two disciplines seem to have a lot in common. Since it is the language that constitutes any text, it is the use of language that outlines the style of the language.

It is possible to make stylistic studies about each period, text and poet/writer. Considering the linguistic scientific dimension of stylistic knowledge, it is possible to draw attention to Saussure's language, which is used to indicate all language phenomena, and its two components, social language and individual qualities. The relationship between language and style is established through "parole“.

\footnotetext{
* Arş. Gör. Dr., Ankara Yıldırım Beyazıt Üniversitesi, İnsan ve Toplum Bilimleri Fakültesi Türk Dili ve Edebiyatı Bölümü Res. Asst. Dr., Ankara Ylldirım Beyazıt University, Faculty of Humanities and Social Sciences, Department of Turkish Language and Literature

ORCID 0000-0001-8422-3049

erciyes_yasar@hotmail.com

Cite as/ Atıf: Tokay, Y. (2020). Kutadgu Bilig'de bir üslup özelliği olarak -sA bolmaz yapısı, Turkish Studies, 15(1), 617-631. https://dx.doi.org/10.29228/TurkishStudies.39623

Received/Geliş: 06 November/Kasım 2019

Accepted/Kabul: 25 February/Şubat 2020

Checked by plagiarism software

Copyright (C) MDE, Turkey 
The history of rhetoric in the West and eloquence in the East can be traced back to ancient / ancient times. The approach of style as a branch of science in modern times is generally based on the work of Western researchers. In 1909, Charles Bally (Traité de Stylistique Française) proposed a style of linguistics as a separate academic discipline to complement the school of Saussure, if we put aside the ancient Indian, Arab and Ancient Greek styles. Thus, Charles Bally directed his linguistic endeavor to the field of literature, where the use of language was more widely seen in separate forms, leading to the emergence of linguistics, a branch of linguistics.

Style analysis requires traditional linguistic levels such as sound, form, structure and meaning. It is observed that style analysis cannot be seen independent of language research. At this point, it should be emphasized that text is the key unit that brings together language and style studies in the common denominator and the necessity of evaluations should be carried out on the language data that manifests itself in the text plane. Stylistics as a branch of science helps to name the elements that make up a literary text. The study of narrative, story and dramatic dialogue is based on the basic units and principles of all forms of linguistic use, namely phonemes, rhythmic order, grammar categories, syntactic order forms, and semantic markers of texts. On the modern stylistic side, problems arise in addressing the relationship between the use of language and its specific context and language as an effective object of the real world. On the other hand, it tries to define the use of special linguistic structures to create copies, models, or distortions of the real world and the language used in the text.

Kutadgu Bilig, as the name suggests, is a work written in Karahanid Turkish which is the standard language of the period in order to show the ways of being happy in every field and branch of both worlds. The work, written as a mesnevi, is not only a politician, it is a guide that gives important information about all points in the life of the society and the individual, sheds light on every stage of the social life and gives advice on various subjects. Grammar and morphology on the basis of the work on the stage of recording a certain point has been reached, while the work was written in the period of Karahanid Turkish and artists are seen to be very little on the stylistic studies.

The conditional mode suffix was -sAr in Old Uighur. But now the personal suffix has started to attach to the attachments and the conditional attraction has occurred. In the Orkhon Inscriptions, it is seen that the sAr in the end of the suffix -sAr conditional, which is in the form of -sAr and is used without being attached to the person pronouns/suffixes, starts to be used in the form of -sA by the end of the Old Uighur period. It can be said that with the exception of a few exceptional examples in Karahanid Turkish, the suffix was used as sA. -sA, which is a conditional suffix in Karahanid Turkish, is in the form of -sAr in the Old Turkish period and is generally used as a gerundium. In the Old Turkish period, certain past tense suffixes with possessive origin suffixes. However, as in other modes, the conditional mode was not used in conjunction with person suffixes or person pronouns of possessive origin. The verb bol- "exist, ocuur", which has been used frequently since the first written documents of the Turkish language, draws attention as a basic and auxiliary verb that provides different usage possibilities from period to period and even from the work in terms of its perifrastic properties.

It has been seen in the sample texts that the $-s A$ bolmaz compound is generally used as a meaning enhancer. The use of the $-s A$ bolmaz phrase in the actual function of proficiency appears to add certainty (often expressed as impossibilities) to the understanding. Eleven of the seventeen samples were used in this semantic framework. The representation or exemplification of said eleven samples by ten separate verbs relates to the variety and richness of the advice given, depending on a stylistic feature. -sA bolmaz structure was determined in the texts where general-pass situations were revealed in four examples. These examples are in line with the proverb content and have a concise word. In the examples discussed, it can be said that the aim is to better convey the advice and place it in mind. In the third use of the $-s A$ bolmaz structure, the subjective thoughts of the author are in the foreground. This situation, which is met only in two examples, suggests that Yusuf Has Hacib sometimes conveys his personal opinions in line with certainty.

As a result, Kutadgu Bilig, one of the most profound and philosophical texts in the history of Turkish language, has a content and style understanding that goes beyond the ages in which it was written. The -sA bolmaz phrase discussed in this article is a small point in the original style of Yusuf Has Hacib. It is thought that different researches on the author's style will have very important results and that the messages of historical texts will be better understood through comparisons and syntheses. 
Keywords: Kutadgu Bilig, style, stylistics, -sA bolmaz.

Öz: Dil ve edebiyat çalışmalarında ortak bir noktada yer alan üslup bilimi (stylistics); oluşturulan edebî metinlerin dil kullanımlarını ve metni oluşturan zihinsel yapıyı ortaya koymada kullanılan bir bilim dalı olarak gelişmiştir. Kutadgu Bilig "Mutluluk Veren Bilgi", isminden de anlaşılacağı üzere hayatın her alanında ve şubesinde, her iki dünyada kutlu olmanın yollarını göstermek için dönemin ölçünlü dili olan Hâkâniye (Karahanlı) Türkçesiyle yazılmış bir eserdir. Mesnevi olarak kaleme alınan eser, sadece bir siyasetname değil toplumun ve bireyin hayatındaki tüm noktalarla ilgili önemli bilgiler veren, sosyal yaşamın her aşamasına 1 şık tutan ve çeşitli konularda nasihatlerde bulunan bir kılavuz niteliği taşır. Eserle ilgili gramer ve morfoloji çalışmaları temelinde aşama kaydedilerek belli bir noktaya gelinmişken, eserin yazıldığı dönem olan Karahanlı Türkçesi devri ve sanatçılarıyla ilgili üslup çalışmalarının pek az olduğu görülür. Kutadgu Bilig'in içerik özellikleri göz önünde bulundurulduğunda bir nasihatname hüviyetinde yazıldığı söylenebilir. Toplumsal değerler, aile yaşamı (eş ve çocuklarla ilişkiler), yeme-içme adabı, konuşma tarzları, çeşitlik mekânlardaki kuralların uygulanması ve sağlık gibi birçok farklı başlık Kutadgu Bilig'in konusunu teşkil etmektedir. Bu konuların anlatıldığı bölümlerde kendine has bir üslubun ve tarzın, eserin her sayfasına yansıdığını söylemek yanlış olmaz. Ana hatlarıyla üslubu oluşturan biçimsel ve anlamsal boyutlar, eserin bir bütün olarak değerlendirilmesi gerektiğine işaret etmektedir. Bu yazıda $-s A$ bolmaz öbeği ele alınarak bu yapının metnin anlam örgüsü içerisindeki yeri, semantik göstergeleri, kullanım alanları ve üslubun oluşumuna katkısı üzerinde durulmuştur. Ele alınan on yedi örnekte $-s A$ bolmaz öbeğinin anlamı üç noktada etkilediği tespit edilmiştir. Anlam çerçevesinin kesinlik, genel-geçerlik ve öznel düşünceler etrafında şekillendiği görülmüştür. Bu yapının aynı zamanda yeterlilik fiili gibi kullanıldığı tespit edilmiştir. Karahanlı Türkçesini takip eden dönemlerde tesadüf edilen örnekler de sıralanarak değerlendirilmiştir.

Anahtar Kelimeler: Kutadgu Bilig, üslup, üslup bilimi, -sA bolmaz.

\section{Giriş}

Üslup (style), bir bilim dalı olarak dil ve edebiyat çalışmalarının kavşak noktasında yer almaktadır. Bu iki farklı disiplinin ortak noktaları oldukça fazla görünmektedir. Herhangi bir metni oluşturan dil olduğuna göre, sahip olunan üslubun çerçevesini çizen de dilin kullanımıdır.

Kökeni Latincedeki "kazık yahut yazmak için ucu sivri alet (kalem)" anlamına gelen stilus'a ve Grekçe stylos'a dayanan, Batı dillerinden Fransızcada stylistique, İngilizcede style veya stylistics, Almancada stilistik, Arapçada uslub veya uslubiyyat veyahut el-uslubiyye ve el-'ilmu'l-uslub olan kavram, Türkçede (Batı dillerindeki eşanlamlı kelimeleri de karşılayacak biçimde Arapçadan geçmiş alıntı bir kelime olarak) hem üslup, biçem, deyiş ve öz anlatı hem de uslubiyyat, üslup ilmi, üslup bilgisi, üslup bilimi, üslupbilim, biçembilgisi, biçembilim ve deyişbilim ile karşılanmaktadır (Çalışkan, 2014: 33-34).

Her devir, metin ve şair/yazar hakkında üslup çalışması yapmak mümkündür. Üslup bilgisinin dil bilimsel boyutu göz önünde bulundurulduğunda Saussure'ün dil olgularının tümünü belirtmek için kullandığ dilyetisi (language) ve onun iki bileşeni olan toplumsal nitelikli dil (langue) ve bireysel nitelik taşıyan $s \ddot{z}$ (parole) kavramlarına dikkat çekilebilir. Dilin üslupla olan ilişkisi "söz" aracılığıyla kurulmaktadır. Dil dizgesinin kullanılışı demek olan "söz"; dilin bir bölümünü geçici olarak eylemli kılar, örneğin somut cümleler kurulmasını sağlar, bireye dili kullanma olanağı veren çeşitli bildirişimlerle bunları dışa ileten anlıksal ve fiziksel bir düzenek içerir (Vardar, 2001: 45-46'den aktaran Karahanci, 2017: 750). Dilbilimde dil/söz ayrımıyla ele alınan bu konuda dil, toplumsal özellikler sergilerken; söz, bireysel tercihlerle kullanılan bir vasıta işlevi görür. Dilin bireysel özellikleri üslubun devreye girmesini sağlar.

Batı'da retorik, Doğu'da ise belagat terimlerinin ön plana çıktığı üslup çalışmalarının tarihi eski/antik zamanlara kadar götürülebilir. Üslubun modern çăglarda bir bilim dalı olarak ele alınması genellikle Batılı araştırmacıların çalışmalarına dayandırılır. Çok eski bir geleneği olan Hint, Arap ve 
Antik Yunan tarzlarını bir kenara koyarsak, 1909'da Charles Bally Fransız Üslûpbilimi Üzerine Inceleme (Traité de Stylistique Française) adlı eserinde Saussure akımını takip eden dilbilimi ekolünü tamamlamak için ayrı bir akademik disiplin olarak üslûpbilimi önermiştir. Böylece, Charles Bally, dilbilimsel çabasını dil kullanımının ayrı biçimlerde daha çok görüldüğü yazın alanına yöneltip, dilbilimin bir kolu olan deyişbilimin doğmasına yol açmıştır (Çalışkan, 2014: 35).

De Vito, üslubu tercihe açık olan dilbilimsel özelliklerin seçimi ve düzenlenmesi olarak kabul eder (De Vito, 1967: 249). Üslubu bir bilim dalı olarak biçembilim karş1lığıyla kullanan Vardar, bu terimi, dilin ya da bireyin araç ve olanaklarını dilbilimsel ilkelerle açıklayan bir disiplin olarak ele alır (Vardar, 1988: 40). Sowinski ise üslubu, bir metinde bilinçli olarak yoğunlaştırılmış ifade tarzını tanımlamak için kullanır (Sowinski, 1991: 164). Crystal'a göre, dilin mevcut olanaklarından bir dizi özelliğin bilinçli ya da bilinçsiz seçimi üslubu oluşturan ana etkenlerdir (Crystal, 1992: 66). Verdonk, stilistik tanımında, dildeki ayırt edici unsurların metin bağlamında tasvir edilebilmesinin amaçlandığını belirtir (Verdonk, 2001: 4). Divlekci'ye göre ise üslup, hedef birime vermek istediği mesajı en etkili şekilde aktarabilmek için, kaynak birimin dilin ifade imkânlarını özgün ölçütlerle seçip kullanmak suretiyle anlatıma kattığı kişisel nitelikteki özelliklerin bütünüdür (Divlekci, 2008: 251).

Üslup incelemesi ses, biçim, yapı ve anlam gibi geleneksel dilbilimsel düzeyleri gerektirir. Üslup incelemesinin dil araştırmasından bağımsız görülemeyeceği doğrultusunda bir sonuca varıldığı gözlenmektedir. Bu noktada dil ve üslup incelemelerini ortak paydada buluşturan anahtar birimin metin olduğu ve değerlendirmelerin de metin düzleminde kendini gösteren dil verileri üzerinden gerçekleştirilme zorunluluğu vurgulanmalıdır (Karahanci, 2016: 157).

Michel Fleischer'in teklif ettiği inceleme yöntemi dört temel aşamadan oluşur.

1. Anlatım bütününün belirlenmesi

2. Üslup elemanlarının belirlenmesi

2a.Kelime elemanları: anlam-kavram açısı, anlam-anlatım açısı, tarihî açı, yöresel açı, sosyal açı, uzmanlık dili açısı, yabancı dil açısı, sözcük yapımı açısı, deyim açısı

2b.Dilbilgisi elemanları: cümlelerin sinfflandırlması (cümle şekilleri, cümle türleri, cümle tipleri), seçmeli cümle öğelerinin yerleri, cümle öğesi sirast, cümle öğeleri ve cümlelerin bağlanması, morfolojik unsurlar

2c.Fonetik Elemanlar: ses taklidi, ses tekrarl, dinamik nüans, melodik nüans, zaman düzenlemesi

3. Üslup özelliklerinin belirlenmesi

4. Üslup tasviri (Fleischer'dan aktaran Yıldız, 1991: 44)

Leech ve Short, üslubu çeşitli kategorilere ayırarak incelemişlerdir:

1. Sözlüksel kategori: adlar, slfatlar, eylemler, zarflar

2. Dilbilgisel kategori: cümle türleri, cümle yapıları, sözcük öbekleri, sözcük türleri sanatlart

3. Değişmeceli dil: dilbilgisel ve sözlüksel yapı taslakları, sesbilgisel yapı taslakları, söz

4. Tutarlılık ve bağlam (Sarıbaş, 2001: 88-89; Tutaş, 2006: 171-172)

Bir bilim dalı olarak stilistik (üslupbilimi), bir edebî metni oluşturan unsurları adlandırmada yardımcı olur. Vezin, hikâye ve dramatik diyalog incelemesi, bütün dilbilimsel kullanım şekillerinin temel birimleri ve ilkeleri, yani sesbirimler, ritmik düzenler, dilbilgisi kategorileri, sözdizimsel düzenleme biçimleri ve metinlerin semantik işaretleyicileri üzerine kurulur. Modern stilistik bir 
taraftan, dilin kullanılış tarzı ile gerçek dünyanın etkin bir nesnesi olarak onun belli bağlamı ve dili arasındaki ilişkiyi ele alma sorunları doğar. Diğer taraftan, gerçek dünyanın ve metinde kullanılan dilin kopyalarını, modellerini veya bozukluklarını yaratmak için özel dilbilimsel yapıların kullanımlarını tanımlamaya çalışır (Bradford, 1997: 2).

\section{Kutadgu Bilig ve Üslup Özellikleri}

Türk dili tarihinin birçok yönden ilklerini barındıran Karahanlı Türkçesi devri, farklı bakış açılarıyla ele alınması gereken özelliklere sahiptir. Özellikle edebî bir metin olmasıyla ön plana çıkan Kutadgu Bilig'in dönemin edebî üslubunu göstermesi bakımından da irdelenmesi gerekir.

Kutadgu Bilig "Mutluluk Veren Bilgi", isminden de anlaşılacağı üzere hayatın her alanında ve şubesinde, her iki dünyada kutlu olmanın yollarını göstermek için dönemin ölçünlü dili olan Hâkâniye (Karahanlı) Türkçesiyle yazılmış bir eserdir. Mesnevi olarak kaleme alınan eser, sadece bir siyasetname değil toplumun ve bireyin hayatındaki tüm noktalarla ilgili önemli bilgiler veren, sosyal yaşamın her aşamasına 1şık tutan ve çeşitli konularda nasihatlerde bulunan bir kılavuz niteliği taşır. Kısacası, Yusuf Has Hacib, temelinde Türk kültürü, örf-adetleri ve siyasî geleneği olan bir yaşam felsefesi ortaya koyar.

Kutadgu Bilig'in metin örgüsü, yazarın ulug aġır ul olarak adlandırdığı dört temel karakter ve unsur üzerine inşa edilmiştir. Dolayısıyla eserin üslubunun oluşmasında bu karakterlerin diyalogları, temsiliyetleri önemli rol oynamıştır. Yusuf Has Hacib'in oluşturduğu ana karakterler yaşamın bütün evrelerini ilgilendiren ve mutluluk yolunu işaret eden değerleri temsil etmiştir. Ana karakter olan Kün Togdl "Güneş Doğdu" hükümdardır ve köni törü "doğru töre/yasa" karşıllğıyla yönetmenin temel vasfi olan adaleti temsil eder. Ay Toldı "Ay Doldu/Dolunay", hükümdarın veziridir ve eserde $k u t$ "Devlet, ikbal, saadet"i temsil eder. Ögdülmiş "Övdürülmüş", Ay Toldı'nın oğludur ve onun vefatından sonra vezirlik makamına geçer. Ögdülmiş, metin örgüsünde, ukuş "Anlayış, idrak"in temsilcisidir. Eserin son ana karakteri olan Odgurmış "Uyan(dırıl)mış" ise insan ömrünün faniliğini soy "akıbet"i işaret eder.

Kutadgu Bilig'in içerik özellikleri göz önünde bulundurulduğunda bir nasihatname hüviyetinde yazıldığı görülür. Toplumsal değerler, aile yaşamı (eş ve çocuklarla ilişkiler), yemeiçme adabı, konuşma tarzları, çeşitlik mekânlardaki kuralların uygulanması ve sağlık gibi birçok farklı başlık Kutadgu Bilig'in konusunu teşkil etmektedir. Bu konuların anlatıldığı bölümlerde kendine has bir üslubun ve tarzın, eserin her sayfasına yansıdı̆̆ını söylemek yanlış olmaz. Ana hatlarıyla üslubu oluşturan biçimsel ve anlamsal boyutlar, eserin bir bütün olarak değerlendirilmesi gerektiğine işaret etmektedir.

Nasihat verirken yazarın kullandığı üslup, bu yazının esasını oluşturmaktadır. $\mathrm{Bu}$ nasihatlerin kimi zaman kesinlik çizgisi kati ifadelerle yer alırken, kimi zaman öznel düşüncelerin üsluba yansıdığı görülür. Bu tip ifadelerin ortak noktası ise $-s A$ bolmaz öbeğinin kullanılmasıdır. Bu yazıda, hem morfolojik hem de semantik yönlerden $-s A$ bolmaz yapısının bir üslup özelliği olarak kullanılması üzerinde durulacaktır.

\section{Kutadgu Bilig'de -sA bolmaz Yapısı ve Üsluba Etkisi}

Karahanlı Türkçesinde şart eki olan $-s A$, Eski Türkçe döneminde $-s A r$ şeklindedir ve genellikle zarf-fiil olarak kullanılmıştır. Eski Türkçe döneminde belirli geçmiş zaman eki iyelik kökenli kişi ekleriyle çekimlenmiştir. Bununla birlikte şart kipi diğer kiplerde olduğu gibi iyelik kökenli kişi ekleri ya da kişi zamirleriyle beraber kullanılmamıştır. Bu dönemde şahıs zamirlerine/eklerine bağlanmadan kullanılması ekin zarf-fiil şeklinde kullanıldığı kanısını güçlendirmektedir. Ayrıca -sAr eki özellikle Orhun Yazıtlarında hem fiil kök ve gövdelerine hem de ek fiile (er-) gelmiştir. Ayrıca çekimli fiillere gelerek birleşik çekim oluşturduğu ve olumsuz şeklinin olumsuzluk ekiyle yapıldığını gösteren örnekler de mevcuttur. Şart eki, Eski Uygurcada da $-s A r$ şeklindedir. Fakat artık kişi eklerine bağlanmaya başlanmış ve şart çekimi oluşmuştur. Orhun 
Yazıtlarında $-s A r$ şeklinde olan ve kişi zamirlerine/eklerine bağlanmadan kullanılan $-s A r$ şart kipi ekinin sonundaki /r/ ünsüzünün, Eski Uygurca döneminin sonlarında düşerek ek $-s A$ şeklinde kullanılmaya başlandığı görülür. Karahanlı Türkçesindeki bir kaç istisnaî örnek dışında ekin tamamen -sA olarak kullanıldığı söylenebilir. Yardımcı cümlesi şart olan bir birleşik cümlenin temel cümlesinde şart kipinin kişi eki almadan kullanılışı, Eski Türkçe ile Karahanlı Türkçesinde ortaklaşa yürüyen bir özelliktir. Ancak, Eski Türkçede şart kipi eki, çekime girip kişi ekleriyle genişletildiğinde, kip ekinin sonuna kişi öğelerini göstermek için kişi zamirleri eklendiği halde (sakınsar sen "düşünürsen", ol yig bolgay üçegü birle ike ölser biz "her üçümüz birlikte ölsek daha iyi olacak" vb.) Karahanlı metinlerinde bu kipin çekiminde artık ara sıra kişi ekleri yanında iyelik eklerinin de kullanıldığı görülmektedir (Bulak, 2011: 79-80). -sA ekinin çağdaş gramer çalışmalarında ele alınış ve tasnif edilişi hakkında farklı düşünceler bulunmaktadır (Kılıçoğlu, 1954; Gülsevin, 1990; Karahan, 1994; Korkmaz, 1995; Develi, 1997; Benzer, 2010; Özdemir, 2013).

Türk dilinin ilk yazılı belgelerinden bu yana sıklıkla kullanılan bol- fiili özellikle perifrastik ${ }^{1}$ özellikleri bakımından dönemden döneme hatta eserden esere farklı kullanım olanakları sağlayan temel ve yardımcı bir fiil olarak dikkat çekmektedir. Tarihî Türk yazı dillerindeki perifrastik yapılarla ilgili ilk çalışmalar, Annemarie von Gabain'e aittir. ${ }^{2}$ Gabain'in perifrastik olarak ele aldığ 1 üç fiil vardır: bol-, er- ve tur- (Gabain, 2000: 129). Ahmet Bican Ercilasun, Kutadgu Bilig'deki er- ve bolfiilleriyle gerçekleştirilen çekimleri, iki kipli çekimler olarak adlandırmıştır (Ercilasun, 1984: 151). Marcel Erdal, er-, bol- ve tur- fiillerini analitik fiil öbekleri (analytical verb phrase) olarak adlandırmış ve örneklerle benzerlikleri ile farklarını ortaya koymuştur (Erdal, 2004: 245-247). Eski Uygurcada perifrastik yapılarla ilgili Fiil $+-m A k+$ bol- kalıplaşmasını ele alan Ağca, bu yapıların sadece Maniheist ve Budist Türkçe metinlerinde kullanıldığını ve "niyet, arzu, yakarış" işleviyle eserlerde yer aldığını göstermiştir (Ağca, 2007).

Türk dilinde belirli işlevlere sahip kimi ek ya da sözcüklerin, tek başlarına ya da başka ek ya da sözcüklerle birleşmek suretiyle bilinen işlevlerine zamanla yeni işlevler kattıkları ya da asıl işlevlerini kaybedip tümüyle başka işlevlerde kullanıldıkları, diğer bir ifadeyle yeni gramer kategorileri meydana getirmek suretiyle gramerleştikleri görülür. Bu bağlamda bazen sözcüklerin ek hâline dönüştükleri, bazen eklerin kalıplaşma ya da görev değişikliği yoluyla asıl işlevlerini bütünüyle ya da kısmen kaybederek başka bir işleve sahip bir ek hâline dönüştüğü bazen de eklerin ya da ek ve yardımcı fiillerin asıl işlevlerinden sıyrılıp bir arada kullanılarak analitik yapılar oluşturmak suretiyle yeni gramer kategorileri oluşturdukları tespit edilmiştir (A ğca, 2007: 4). Türk dilinde zaman ve kip çekimlerinde kullanılan bir takım eklerin de, asıl işlevlerinden sıyrılarak yeni işlevler kazanmak suretiyle ortaya çıktıkları bilinmektedir (Ağca, 2007: 4).

\footnotetext{
1 Kökeni Yunanca olan periphrazen "dolaylı yoldan konuşmak; değiştirip yazmak" sözcüğü Latinceye periphrasis biçiminde geçmiştir. Bu terim genel olarak bir kelime ile ifade edilebilecek bir anlamın dolaylı yollardan birden fazla dil birimiyle ifade edilme yöntemi olarak açıklanabilir. Eski Latin gramerlerinde conjugatio periphrastica terimi kullanılırken, bu terimle kast edilen dilde çok fazla karşılaşılmayan ve bir kaç sözlükbirimin birleşmesiyle oluşan yapılardır (Haspelmath 2000: 655). Matthews, perifrasis terimini, iki ya da daha fazla sözcüğün birleşerek oluşturduğu paradigmalar bütünü olarak tanımlar (Matthews 1981: 55). Trask, birden fazla yardımcı fiilin bulunduğu özellikli olarak yeni bir eylem biçimi oluşturan yapıları bu başlık içine dâhil etmiştir (Trask 1993: 12). Bonami, iki ayrı sözlük birimin bir araya gelmesiyle oluşan dolaylı fiil çekimini perifrasis olarak adlandırmıştır (Bonami 2015: 64). Demir, Türkçedeki perifrastik yapıları incelediği çalışmasında bu terimi, çekim morfolojisindeki boşlukların doldurulamadığı durumlarda herhangi bir sözcükbirimin zaman, görünüş, kutup gibi unsurlarla karşılandığı takımların genel adı olarak tanımlar. Kısacası dilde ortaya çıkan boşluklar perifrastik işaretleyicilerle doldurulmaktadır (Demir 2015:5).

${ }^{2}$ Türkçedeki -özellikle Türkiye Türkçesindeki- perifrastik yapılarla ilgili çok sayıda çalışma bulunmaktadır. Batı dillerinde kullanılan periphrasis sözcüğüne verilen bazı Türkçe karşılıklara bakmak faydalı olacaktır. Türkçede perifrasis terimine karşılık olarak yerindelik (Deny [Elöve] 1941: 465), dolaylama (Vardar vd. 1988: 84), dolambaçlllık (Karabulut 2011: 180), artıklı çekim (Karaağaç 2013: 156), çevrik fiil (Banguoğlu 2000: 451) karşılıkları kullanılmıştır.
} 
Şart eki -sA, bol- fiili ve geniş zaman olumsuzluk biçimi olan - $m A z$ ekinin birleşimiyle ortaya çıkan ve bir üslup özelliği olarak ele alınan -sA bolmaz öbeğinin Kutadgu Bilig'de kalıplaşmış bir biçimde karşımıza çıktığını söylenebilir. Bu kalıplaşma neticesinde metin örgüsünde farklı anlam boyutları oluştuğu örnek şiirlerden takip edilebilmektedir.

\subsection{Kutadgu Bilig'de -sA bolmaz Öbeği}

Kutadgu Bilig'de çok dikkat çekici perifrastik yapılardan biri -sA bolmaz öbeğidir. Şart eki $s A$ ve bol- yardımcı fiilinin bileşiminden oluşan bu yapının semantik çerçevesi bir hayli geniştir. Metinlerde tespit edilen örneklerin daha çok "nasihat, öğüt" niteliğinde olan beyitlere yerleştirildiği görülür. Bu perifrastik öbek, şart anlamından ziyade yapılmaması gereken davranışların kesinlik çizgisine katkıda bulunmuştur. Bu noktada bol- fiilinin geniş zaman olumsuzluk sıfat-fiiliyle birleşerek anlamı pekiştirdiği açıktır. Bizce, bu kullanımlar eserin yazarı olan Balasagunlu Yusuf'un üslup özelliğiyle alakalıdır. Genel olarak bir nasihat metni kabul edilen Kutadgu Bilig, metinlerin içerisine yerleştirilen -sA bolmaz gibi öbeklerle anlamsal bütünlük gösteren bir yapıt olarak dikkate değerdir. Verilen nasihatin/mesajın etkisi bu tip yapılarla güçlendirilmiş ve okuyucunun odak noktas1 haline getirilmiştir. Kutadgu Bilig'de -sA bolmaz öbeğinin on yedi kez kullanıldığı tespit edilmiştir. $\mathrm{Bu}$ kullanımlar semantik açıdan çeşitli başlıklar halinde ele alınabilir.

Tespit edebildiğimiz kadarıyla $-s A$ bolmaz öbeğinin yeterlilik fiili işlevinde kullanılarak anlama kesinlik (çoğu zaman imkânsızlıklar ifade edilir) kattı̆̆ı görülür. On yedi örneğin on biri bu semantik çerçevede kullanılmıştır. Kesinlik anlamı verilerek anlamı pekiştirilen sözcükler sırasıyla kizle- "gizlemek", tut- "Yetişmek, yakalamak", bul- "Bulmak", tur- "Hareketsiz kalmak", uk"Anlamak", yet- "Yetişmek", et- "Düzene sokmak", sür- "Devam etmek", yanut kıl- "Karş1lık vermek", bil- "Bilmek" fiilleridir.

-sA bolmaz öbeğinin hangi konulara dair örneklerde geçtiği konusunu dikkate alacak olursak karşımıza sosyal hayatı doğrudan ilgilendiren ya da bireyin kişilik oluşumuna katkı sağlayacak meselelerin tercih edildiği görülür. Bu konular arasında hayatın geçiciliği, dilin doğru kullanımı, sözün değeri, dilek ve arzulara kavuşma, çok çalışmak ve vazgeçmemek, bilginin önemi, devlet işlerinin zamanında yapılması, ordunun düzen ve nizamının korunması, devlet idaresi ve canlıların fitratlarıyla ilgili ifadeler dikkat çekmektedir. Bu öbeğin kullanımında farklı fiillerin tercih edilmesi ve konuların çeşitliliği eserin, toplumun ve bireyin yaşamındaki her duruma ait fikirler sunmasıyla açıklanabilir.

(1) Yoparlı biligli teni bir yayı

Tutup kizlese bolmaz özde öyi (KB 311)

"Miski (güzel kokuyu) gizlesen de kokusundan belli olur. Kendinden (O) (kokuyu) başka bir şekilde de gizleyemezsin." ${ }^{3}$

Tiriglik tidükü̈ bu yel teg keçer

Kaçar tutsa bolmaz anı kim bulur (KB 693)

"Bu hayat dediğin yel gibi geçer, tutamazsın, kaçar, onu (sonra) kim bulabilir."

\section{Tilek bulsa bolmaz tiriglik yigü}

Tirig bolsa bulmaz tilek ay bügü (KB 1123)

"Ey bilgili insan! Dileğini bulan kişi hayatını yaşayamaz. Hayatını yaşayan kişi ise dilediklerini bulamaz."

\footnotetext{
${ }^{3}$ Metinlerin Türkiye Türkçesine aktarımında, Reşit Rahmeti Arat'ın, Kutadgu Bilig II: Çeviri (1985) adlı çalışması kullanılmıştır.
} 
(4) Apa oglanı körse arkış sanı

Örüg turgu bolmaz örügler kanı (KB 1386)

"İnsanoğlu bir kervan gibidir. Devamlı duramaz (mola veremez), yeni menziller nerede?"

(5) Kişi ögrenür bilgi artar üküş

Neçe ögrenip uksa bolmaz ukuş (KB 1827) elde edemez."

"İnsan çok şeyler öğrenir ve bilgisi artar. Fakat ne kadar öğrenirse öğrensin, (gerçek) aklı

(6) Ödinde keçürse bu beglik işin

Ant yetse bolmaz ederse kuşın (KB 2094)

"Devlet işleri ihmal edilir ve vaktinde yapılmazsa, arkasından avcı kuşlarla takip etsen bile tekrar yetişemezsin."

(7) Kalın sü yayılsa için bulgaşur

Anı etse bolmaz yaragsız tuşur (KB 2336) gösterir."

"Kalabalık ordu (iyice) yayılınca içten içe karışır, nizama sokulamaz ve kötü durumlar baş

(8) Kllıç birle alsa kayu el küçün

Anı sürse bolmaz üküş yıl öçün (KB 2427)

"Herhangi bir memleket kılıç ve kuvvetle alınabilir. Fakat bu hâkimiyet, şiddet ve intikam duygusuyla, uzun yıllar devam ettirilemez."

(9) Tilemişte bulsa tilegli negin

Yanut kılsa bolmaz canında öyin (KB 2819)

"İsteyen kişi dileklerini istediği zamanda bulursa, buna canından başka verecek bir karşıllı̆ 1 olamaz."

\section{Boşug kul bile tutsa bolmaz bu tüz}

Boşug boş tẹi tut kulug kulça üz (KB 2991)

"Özgür bir insan ile köle bir tutulamaz. Özgür insana özgür bir insana uygun şekilde, köleye ise bir köleye uygun şekilde muamele et!"

\section{Tükel bilse bolmaz kllıklarını}

Yime alsa bolmaz alıklarını (KB 4757)

"Onların tabiatları tamamıla bilinemez. Yapacakları fenalıkların hepsi engellenemez."

-sA bolmaz öbeği, dört örnekte genel-geçer durumların ortaya konduğu metinlerde tespit edilmiştir. Bu örneklerde anlama kesinlik katmaktan ziyade, bahsedilen olgunun değişmeyeceği ve hep aynı şekilde sürüp gideceği ele alınmıştır.

Tespit edilen dört örnekte sök- "Sövmek", ti- "Söylemek" (iki kez), işlet- "Iş̧ yapmak, çalışmak" fiilleri kullanılmıştır. sök- fiiliyle dilin ve sözün önemi, ti- fiiliyle bilginin değeri, işletfiiliyle ise zaman yönetiminin ne kadar kıymetli olduğu üzerinde nasihatler verilmiştir.

(1) Tilig sökse bolmaz telim öggüsi

Sözüg öggüsi bar yime sökgüsi (KB 1020) 
"Dile yalnızca sövülmez, övülecek tarafı da çoktur. Aynı şekilde sözün de övgüsü ve yerilecek noktaları vardır."

(2) Bilig tegmese kimke erse ülüg

Tirig tise bolmaz anı tut ölüg (KB 2450)

"Bir kimse bilgiden nasibini almamış ise ona diri demek doğru olmaz, sen onu ölü bil!"

(3) İdi klz erür bu tiriglik küni

Yawa işke işletse bolmaz munı (KB 3544)

"Bu hayatın her günü çok değerlidir. Bunu boş yere sarf etmek doğru değildir."

Yawuz tise bolmaz bu dünya nenin

Yise berse halkka klzartsa ejin (KB 3977)

"Bu dünya malını kötülemek doğru değildir. Bunu sarf etmek ve dağıtmak yoluyla halkı mutlu etmek de mümkündür."

-sA bolmaz öbeğinin üçüncü kullanımında ise yazarın öznel düşünceleri ön planda yer alır. Yalnızca iki örnekte karşılan bu durum, Yusuf Has Hacib'in şahsi kanaatlerini kimi zaman kesinlik çizgisi içerisinde aktardığını düşündürmektedir. Şüphesiz bu durum, yazarın yetiştiği toplumun düşünce tarzı ile bireysel ahlakının birleşiminden doğan yansımalardan oluşmaktadır.

Yazar, öznel ifadelerine yer verirken küçe- "Zorlamak" ve yawa kıl- "Heba etmek, boşa harcamak" fiillerini tercih etmiştir. Örneklerden de anlaşılacağ1 üzere dürüstlük ve zamanı doğru kullanmanın önemi vurgulanmıştır.

$$
\text { Ol aymış sözüg körse barça köni }
$$

Küçese yime bolmaz emdi anı (KB 4922)

"Dikkat edersen söylediklerinin hepsi doğrudur. Şimdi onu zorlamak olmaz."

\section{Bayat berdi bizke bu kün bu künüg}

Yawa kılsa bolmaz bu bulmış ödüg (KB 6408)

"Tanrı bize, bugün bu günü verdi. Ele geçen bu firsatı boşa harcamamak gerekir."

Kutadgu Bilig'de, -sA bolmaz öbeğinin kullanımının yanı sıra, bu yapının olumlu işaretleyicisi olarak kullanılan $-s A$ bolur öbeğine de tesadüf edilir. Ancak bu örneklerin birebir $-s A$ bolmaz öbeğinin semantik karşıtı olduğunu söylemek doğru olmaz. Yazar, bahsedilen örneklerde tamamen şahsi görüşlerine yer vermiștir ve bu doğrultuda semantik çeșitlilik -sA bolmaz yapısına göre tekdüzedir. $\mathrm{Bu}$ durum eserde bir üslup işaretleyicisi olarak esas kullanımın -sA bolmaz öbeği olduğunu göstermektedir.

Kutadgu Bilig'de -sA bolur öbeğinin yer aldığı dört örnek tespit edilmiştir. Özellikle metin bağlamında ınan- fiilinin anlamsal bir kalıplaşmaya uğrayarak kullanılması da dikkat çekicidir. Şüphesiz bu durum, ınan- "İnanmak" fiilinin anlamını kuvvetlendirmeye yönelik bir birlikteliktir.

(1) Anar ötrü begler inansa bolur

Tilemis tilekin beg andin bulur (KB 2416)

"Böyle bir adama beyler inanabilirler. Beyler, onun vasıtasıyla arzu ettiği şeyi bulur."

(2) Bu yaylıg kişike inansa bolur

Kişilik tilese anıฤdın kelür (KB 2738)

www.turkishstudies.net/turkishstudies 
"Böyle bir insana inanmak mümkündür. İnsanlık ararsan onda bulursun."

(3) Özüy 'ukbi kolsa az zahid bulur

Muyan edgü mundın iletse bolur (KB 3976) olabilirsin."

"Ey zahit! Eğer ahireti istiyorsan, onu da bulursun. Orada da nimet ve sevaba nail

(4) Tapugka negü teg Inansa bolur

Tapındım tiyü bilse müflis kalur (KB 3985)

"İbadete nasıl inanırsan (o şekilde) kabul edebilirsin. İnsan hakkıyla ibadet ettiğini düşünürse, yaptığı ibadetler boşa gider."

Kutadgu Bilig'de bir üslup özelliği olarak kullanıldığını düşündüğümüz -sA bolmaz öbeğinin sonraki dönem edebî metinlerinde de kullanıldığı görülür.

Kutadgu Bilig'le aynı dönemde kaleme alınmış Divanü Lugati't-Türk'te -sA bolmas öbeğinin kullanıldığı iki örnek tespit edilmiştir. Ancak Kâşgârlı, bu yapıdan bir gramer özelliği olarak bahsetmemiştir. Örneklerden biri titin- fiilinin açıklanmasında kullanılırken, diğeri bir atasözü içerisinde yer almıştır. İki örnekte de -sA bolmas öbeğinin yeterlilik fiilinin olumsuzluk fonksiyonuna sahip olduğu ve fiile -e bil(-me-) anlamı kattığı görülür: bakamaz."

(1) Anıy yüzinge titünü baksa bolmas "İnsan, onun güzelliği dolayısıyla yüzüne bile (dik dik)

(2) Telim sözüg uksa bolmas, yalım ḳaya yıksa bolmas "İnsan, çok sözü anlayamaz, dağdaki yalçın kayayı yıkamaz." (Bu sav, sözü uzatması istenen kimse için söylenir.)

Harezm Türkçesi eserlerinden olan Mu înü'l-Mürîd'de -sA bolmas öbeğinin kullanıldığı dört örnek tespit edilmiştir. Bu öbeğin örneklerde, net bir şekilde, yeterlilik fiili gibi kullanıldığ görülür:

(1) Hiläf ḳlsa bolmas bilin muktedi

Imāmnuy soyınça kim uydum tèdi

Kullp tevbe dostlar irādet bèriy

Ölüp tevbesiz köp ökünçler yédi (MM 273) (Toparl1-Argunşah, 2018: 132)

"(Şöyle) bilin! İmamın arkasında durup da ona uydum diyen muktedî/inanan sözünden dönemez. Dostlarım, tövbe edip nefsinizi terk edin. Tövbe ölenler çok pişman oldu."

(2) Asig ḳlmas ol köp ökünç yèse soy

$\dot{E}$ r ol kim oyarsa işin munda öy

Ecelnị hazānı kèlür nāgehān

Urug èkse bolmas kirür yèrge ton (MM 274)

"İnsan, sonradan çok pişman olsa da fayda etmez. (Akı1lı) insan, işini başından düzgün yapıp tertip eden kişidir. Ecelin hazanı aniden gelir, (o) (zaman) toprağa don düşeceği için tohum ekemezsin."

(3) Ürü̈ üzre nūrdın bitilmiş bitig

Oḳp uksa bolmas munı köp tètik

Yonar mu ayıtġll bıçak öz özin

Nęçe bolsa edgü bilenmiş yitig (MM 330) 
"Beyaz üstüne nurdan kitap yazılmış. Birçok akıllı insan (bile) bunu okuyup anlayamaz. Söyle (bana)! Ne kadar iyi bilinmiş ve keskin olursa olsun bıçak (hiç) kendini keser mi!"

(4) Bilig bilmiş üçün 'àlimler birer

Öyinler cāhil tèp tekellüf kurar

Bilig bildi èrse bu Mūsā tèg ök

Cāhil tèse bolmas Hiżır tègtür èr (MM 394)

"Âlimler, çok bilgili oldukları için kimi zaman diğer insanların cahil olduğunu söyleyip gösteriş yaparlar. İnsan Hz. Musa kadar bilgili olsa dahi kimseye cahil diyemez/dememelidir, (tıpkı) Hizır a.s. gibi."

Harezm Türkçesinin önemli edebî metinlerinden olan Hüsrev ü Şî̂িn'de (HŞ) -sA bolmaz yapısının oldukça yaygın bir kullanımı olduğu tespit edilmiştir. Öyle ki, HŞ'de saptanan örnekler, KB'de kullanılan örneklerden sayıca daha fazladır. HŞ'deki örneklerde hem yeterlilik fiilinin olumsuzu fonksiyonu hem de KB'de olduğu gibi anlamı kesinleştirmek ve pekiştirmek için kullanılan perifrastik özellikleri dikkat çekicidir.

(1) Ḳılıp kurbān ḳuwu ördek tawuk kaz

Uş ança kim hisābın ḳllsa bolmaz (HŞ 1054) (Hacieminoğlu, 2000: 242)

(2) Şîrînsiz könli ārām ḳllmaz èrdi

Velî hem mülk koysa bolmaz èrdi (HŞ 1220)

(3) Uş ança halk birle ḳldı i'zāz

Kim ol yüz beyt içinde aysa bolmaz (HŞ 1238)

(4) Burunkı zevk hîç soyra tapulmaz

Karllıkda yigitlik kalsa bolmaz (HŞ 1477)

(5) Bu tünni ḩoş tutalıy kim tapulmaz

Yiterbiz tayka tip hükm ètse bolmaz (HŞ 1661)

(6) Ulaş bu ḩanda şekker yise bolmaz

Hemîşe zevk ḳlg̀an tise bolmaz (HŞ 1794)

(7) Bu devletsiz ulugilug $\mathbf{k}$ llsa bolmaz

Biter iş bolsa devlet hîç kalmaz (HŞ 1855)

(8) Suwı köp bolsa hoş meyve bèrür bāà

Ewünsüz kursa bolmaz kuşka hîç ag (HŞ 1858)

(9) Tişide kèlgey èrlik tise bolmaz

Kim èrmen tigüçilerdin tapulmaz (HŞ 2130)

(10) Velî saḳlar men öz pādşāhlıḳmnı

Kim ol terk ètse bolmaz şāhlıḳımnı (HŞ 2151)

(11) Ėw ogrrisınga esşik yapsa bolmaz

Eger yapsay taḳı hîç fāide ḳılmaz (HŞ 2246) 
(12) Inansa bolmaz uş ajunḳa hergiz

Nèler iştip baḳı nèler körer biz (HŞ 2736)

(13) Anıฤ tèg haddidin artuk kılur nāz

Kim imdi hîç tahammül ḳlsa bolmaz (HŞ 3090)

(14) Nè iş kim kèlse èldin ḳlsa bolmaz

Yana soy né kèlürin bilse bolmaz (HŞ 3354)

(15) Kaytıp yoluĐça yèter men tise bolmaz

Kişi yurtında köçün konsa bolmaz (HŞ 3519)

(16) Kamug 'āşılknı bir tèk sansa bolmaz

Kamug miskin ḳanındın kansa bolmaz (HŞ 3552)

(17) Kim ol özinge nè bolsa kolmaz

Velî küç birle rūz, keltürse bolmaz (HŞ 3608)

(18) Şîîn aytur bu sözler bile bolmaz

'Āşıklar kolmaşını bilse bolmaz (HŞ 3634)

(19) Cefā ḳldı tiyü hîç körklülerdin

Köyülni kesse bolmaz tartg்u nāzın (HŞ 3698)

(20) É Elig kökdeki ayg்a sunsa bolmaz

Ayar hodrāyllk itip münse bolmaz (HŞ 3706)

(21) Ágaç kim evvelinde ègri bitse

Anı ot bolmasa bolmaz tüzetse (HŞ 4267)

(22) Bu topdın taşra sakış ḳlsa bolmaz

Anı bir tẹridin öy kimse bilmes (HŞ 4286)

(23) Cevāb aydı kim uşbu perdedin rāz

Açılmadı kişige bilse bolmaz (HŞ 4296)

(24) Nèteg kim cānsızın ten işke kèlmez

Yana tensiz bu cānnı bilse bolmaz (HŞ 4310)

(25) Ölümdin sözlegen köp bilse bolmaz

Ölümni ölmedin hîç kimse bilmez (HŞ 4354)

(26) Körer sen hîç nè èrse bāk̂î kalmaz

Ajunda tutşu hanlık k̆lsa bolmaz (HŞ 4623)

Memluk Kıpçak Türkçesiyle kaleme alınmış tek edebî eser olan Kitâbu Gülistân bi't-Türkî'de de üç örnek tespit edilmiştir. Eserde tespit edilen örneklerin yardımcı fiil èt- ile kalıplaştığı söylenebilir.

Atımnı̀ arpası bolmasa yā eyerimniך içirgisi tutsak bolsa sulțān kullarına altun bilen bahıllık kulsa cān bilen aya comardlık ètse bolmas (GT 22b13-23a1-3) (Karamanlığlu, 1989) 
"Atımın arpası olmasa ya da eyerimin keçesini tutacak olsa sultan kullarına altın ile cimrilik etse daha uygun olur; ancak canıyla ona cömertlik etmemelidir/edemez."

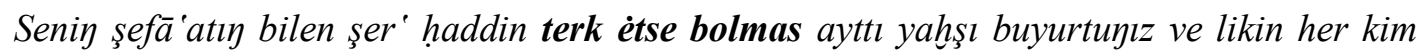
vakfdan nème og̀urlarsa aya kat làzım bolmas (GT 56b12-13-57a1-2) "Senin şefaatinle kötülükleri terk edemez. Şöyle söyledi: Doğru ve güzel buyurdunuz; ancak vakıftan para çalan herkesi kesmek gerekmez."

Melikler dostlukına i timād ètse bolmas dagì og̀lanlarnıy hoş āvāzına kim ol bir hayāl bilen mübeddel bolur dag் bu yigitlik bilen mütegayyir bolur (GT 161b11-162a1) "Meliklerin dostluğuna ve oğlanların güzel sesine çok fazla güvenilmez. Çünkü o bir hayal ile değişir ve bu gençlik ile farklılıklar ortaya çıkar."

\section{Sonuç}

Kutadgu Bilig'de şart eki $-s A$ ve bol- fiilinin geniş zaman olumsuzluk biçimi olan $-m A z$ birimiyle birleşerek kullanılan -sA bolmaz öbeği, eserin üslubuna doğrudan etki eden bir unsur olarak yer verilmiştir. Türk dilinin her döneminde rastlanan sözlükbirim +sözlükbirim (et+öz "Vücut" gibi), biçimbirim +biçimbirim (-dUkdA, -mAkdA gibi) ve biçimbirim +sözlükbirim (kel-miş bol-, kel-ür bolgibi) birleşikler bulunmaktadır. Özellikle biçimbirim+sözlükbirim yapısında gelişen örnekler bolfiilinin perifrastik özellikleri ön plana çıar. Kutadgu Bilig'de tespit ettiğimiz $-s A$ bolmaz öbeğinde de bu perifrastik oluşum dikkat çeker. Bu öbeğe eserde on yedi kez tesadüf edilmiştir. Örneklerin nasihat metinlerinde yer alması, yazarın bu konuda özel bir hassasiyet gösterdiğini düşündürmektedir.

Örnek metinlerde -sA bolmaz birleşiğinin genellikle anlam kuvvetlendiricisi olarak kullanıldığı görülmüştür. $-s A$ bolmaz öbeğinin yeterlilik fiili işlevinde kullanılarak anlama kesinlik (çoğu zaman imkânsızlıklar ifade edilir) kattığı görülür. On yedi örneğin on biri bu semantik çerçevede kullanılmıştır. Bahsedilen on bir örneğin on ayrı fiille temsil edilmesi ya da örneklendirilmesi, bir üslup özelliğine bağlı olarak verilen öğütlerin çeşitliliği ve zenginliği ile ilgilidir.

-sA bolmaz öbeği, dört örnekte genel-geçer durumların ortaya konduğu metinlerde tespit edilmiştir. Bu örnekler atasözü içeriğine yakın bir çizgide bulunmaktadır ve özlü söz hüviyeti taşırlar. Ele alınan örneklerde, verilen nasihatin daha iyi aktarılması ve akılda yer etmesi amacının güdüldüğü söylenebilir.

-sA bolmaz öbeğinin üçüncü kullanımında ise yazarın öznel/subjektif düşünceleri ön planda yer alır. Yalnızca iki örnekte karşılan bu durum, Yusuf Has Hacib'in şahsi kanaatlerini kimi zaman kesinlik çizgisi içerisinde aktardığını düşündürmektedir.

Kutadgu Bilig'de, -sA bolmaz öbeğinin kullanımının yanı sıra, bu yapının olumlu işaretleyicisi olarak kullanılan $-s A$ bolur öbeğine de tesadüf edilir. Ancak bu örneklerin birebir $-s A$ bolmaz öbeğinin semantik karşıtı olduğunu söylemek doğru olmaz. -sA bolur öbeği, -sA bolmaz yapısı kadar çeşitli olmadığı gibi üsluba da doğrudan etki etmemiştir.

Göktürkçe ve Uygurcada görülmeyen, ilk örneklerine Karahanlı Türkçesi eseri olan Kutadgu Bilig'de tesadüf ettiğimiz -sA bolmaz öbeğine aynı dönemde yazılmış eserlerden yalnızca Divanü Lugati't-Türk'te rastlanılması ve sözlükte, bu yapının sadece iki kez kullanılmış olması, -sA bolmaz öbeğinin Yusuf Has Hacib'in dili kullanma ustalığ 1 ve üslup özellikleriyle alakalı olduğunu işaret etmektedir. Nitekim Karahanlı Türkçesini takip eden devrelerden olan ve ses-şekil yönlerinden Karahanlı Türkçesi geleneğini devam ettiren Harezm Türkçesi metinlerinde aynı yapıya sıklıkla tesadüf edilmesi, Yusuf Has Hacib'in kendinden sonra gelen edipleri/yazarları etkilediğini göstermektedir. Bu öbeğin hem Mu' înü'l-Mürîd'de (4 kez), hem de Hüsrev ü Şîrîn'de (26 kez) yer alması, özellikle edebî metinlerde oluşan üslup özelliklerinin devamı niteliğindedir. Harezm 
Türkçesi eserleri dışında, Memluk Kıpçak Türkçesinin tek edebî eseri olan Gülistan Tercümesi'nde bu öbek üç kez yer bulabilmiştir. KB'de tespit edilen örneklerle HŞ'de kullanılan örnekler arasında yakın ilgi de gözden kaçmamaktadır. Her iki eserin de beyitlerle yazılmış olması, tespit edilen örneklerin genellikle atasözleri ya da özlü sözler içerisinde yer alarak ögüt vermesi ve gramatikal yönden yeterlilik fiili gibi kullanılması önemli ortak özellikler olarak göze çarpar.

Sonuç olarak, Türk dili tarihinin en derin ve felsefî metinlerinden biri olan Kutadgu Bilig, yazıldığı çağları aşan bir içerik ve üslup anlayışına sahiptir. Bu yazıda ele alınan -sA bolmaz öbeği, Yusuf Has Hacib'in özgün üslubu içerisinde küçük bir noktadır. Üstelik bu üslubun özellikle Harezm Türkçesi sanatçısı Kutb tarafından sürdürüldügü açıkça görülmektedir. Yazarın ve kendisinden sonra gelen edebî şahsiyetlerin üslupları üzerine yapılacak karşılaştırmalı araştırmaların çok önemli sonuçlar doğuracağı, tahlil, mukayese ve sentezlerle tarihî metinlerin verdiği mesajların daha iyi anlaşılacağ1 düşünülmektedir.

\section{Kaynakça}

Ağca, F. (2007). Manihesit ve Budist Türkçe Metinlerde Fiil $+-m A k+\dot{y} E E k$ bol- Yapısı Üzerine, Türkbilig, S. 14, 3-21.

Arat, R. R. (1979). Kutadgu Bilig III: Indeks. (haz. Kemal Eraslan, Osman Fikri Sertkaya, Nuri Yüce), İstanbul: TKAE Yayınları.

Arat, R. R. (1985). Kutadgu Bilig II: Çeviri. Ankara: TTK Yayınları.

Arat, R. R. (1991). Kutadgu Bilig I: Metin. Ankara: TDK Yayınları.

Aydemir, H. (2013). "Bir Nöbetleşme Hadisesi ve -sA Şart Ekine Yansımaları", Karadeniz Araştırmaları, S. 37, 199-207.

Banguoğlu, T. (2000). Türkçenin Grameri. Ankara: TDK Yayınları.

Benzer, A. (2010). "-sA Ekinin İşlevleri ve Dilek-Şart Ayrımı". SÜ Türkiyat AraştırmalarıDergisi, Sayı: 28, 131-140.

Bonami, O.(2015). Periphrasis as Collocation. Morphology 25, 63-110.

Bradford, R. (1997). Stylistics. London and New York: Routledge.

Bulak, Ş. (2011). "Tarihî ve Çağdaş Türk Yazı Dillerinde Şart Kipi", SÜ Türkiyat Araştırmaları Dergisi, S. 30, 71-97.

Çalışkan, A.(2014). Üslûp ve Üslûpbilim Üzerine-1: İlk Belirlemeler. Uluslararası Sosyal Araştırmalar Dergisi, C. 7, S. 34, 29-52.

Demir, İ. (2015). Türkçede Perifrasis (Fiil Çekim Kategorisi). Ankara: Gazi Kitabevi.

Deny, J.(1941). Türk Dil Bilgisi. çev. Ali Ulvi Elöve, İstanbul: TDK Yayınları.

Develi, H. (1997). “ $\{\mathrm{Sa}\}$ Morfemli Yardımcı Cümleler ve Bunlarla Kurulan Birleşik Cümleler Üzerinde Bir İnceleme”, TDAY Belleten 1995, TDK Yayınları, Ankara, 115-152.

De Vito, J. (1967). Style and Stylistics: An Attempt at Definition, Quarterly Journal of Speech, 53(3), 248-255.

Divlekci, C. (2008). Tarihsel Süreç İçerisinde Üslûba İlişkin Tanım Çabaları ve Bir Tanım Denemesi-II. Ankara Üniversitesi İlahiyat Fakültesi Dergisi, Ankara: Ankara Üniversitesi Yayınları, C. XLIX, S. I, 223-252.

Ercilasun, A. B. (1984). Kutadgu Bilig Grameri: Fiil. Ankara: Gazi Üniversitesi Yayınları. 
Erdal, M. (2004). A Grammar of Old Turkic. Leiden-Boston: Brill.

Gabain, A. v. (1974). Alttürkische Grammatik. Wiesbaden.

Gabain, A. v. (2000). Eski Türkçenin Grameri. çev. Mehmet Akalın, Ankara: TDK Yayınları.

Gülsevin, G. (1990). "Türkçede Şart Gerundiumu Üzerine", Türk Dili, S. 467 (2), 276-279.

Hacıeminoğlu, N. (2000). Kutb'un Husrev ü Şirin'i ve Dil Hususiyetleri. Ankara: TDK Yayınları.

Haspelmath, M.(2000). Periphrasis, Morphology: A Handbook on Inflection and Word Formation. p. 654-664, Berlin: Walter de Gruyter.

Karaağaç, G. (2013). Dilbilim Terimleri Sözlüğü. Ankara: TDK Yayınları.

Karabulut, F. (2011). Türk Dilinde ve Dünya Dillerinde Edilgen Yapı Tipolojisi: Dilbilimsel Bir Inceleme. Ankara: Grafiker Yayınları.

Karahan, L. (1994). "-sa / -se" Eki Hakkında", Türk Dili 516 (Aralık), 471-474.

Karahanci, İ. (2016). Üslup Belirleme Girişimlerine Dil Verileri Üzerinden Yaklaşmak.Uluslararası Sosyal Araştırmalar Dergisi, 9(45), 154-161.

Karahanci, İ. (2017). Sözcük Birimlerin Üslup Oluşumuna Katkısı II. Uluslararası Türkçe Edebiyat Kültür Eğitim Dergisi, 6/2, 749-768.

Karamanlığlu, A. F. (1989). Seyf-i Sarâŷ̂, Gülistân Tercümesi (Kitâb Gülistân bi't-Türkî), Ankara: TDK Yayınları.

Kılıçoğlu, V. (1954). "Şart Kipi". Türk Dili, C. III sayı: 29, 254-258.

Korkmaz, Z. (1995). "-sa/-se Dilek - Şart Kipi Eklerinde Bir Yapı Birliği Var Mıdır?". Türk Dili Üzerine Araştırmalar I, TDK Yayınları, 160-167.

Matthews, P. H. (1981). Morphology. Cambridge: Cambridge University Press.

Sarıbaş, T. (2001). Nesnellik Öznellik İkileminde Biçembilim ve Düzyazı Çözümlemesi için Bir Yöntem: Sabahattin Ali'nin 'Kağnı' Adlı Öyküsü. Dilbilim ve Uygulamaları, S. 2, 81-95.

Sowinski, B. (1991). Stilistik. Stiltheorien und Stilanalysen. Stuttgart: Metzler.

Toparlı, R.-Argunşah, M. (2018). Mu înü'l-Mürîd. Ankara: TDK Yayınları.

Trask, R. L. (1993). A Dictionary of Grammatical Terms in Linguistics. London-New York: Routledge.

Tutaş, N. (2006). Yazınsal Metinlerde Biçembilimsel İnceleme. Littera Edebiyat Yazıları, Ankara Hacette Üniversitesi Yayınlar1, (haz.) Cengiz Erdem, C. 19, 169-180.

Vardar, B. (1988). Açıklamalı Dilbilim Terimleri Sözlüğü. İstanbul: ABC Yayınları.

Verdonk, P. (2001). Stylistics. Oxford: Oxford University Press.

Yıldız, C. (1991). Üslup ve Üslup İnceleme Metotları, Yayımlanmamış Yüksek LisansTezi, İstanbul: Marmara Üniversitesi Sosyal Bilimler Enstitüsü. 